\title{
Correlation Between Body Mass Index and Lipid Profile in a Diabetic Population of Central Nepal
}

\author{
Prerna Bansal, ${ }^{1}$ Hari Prasad Upadhyay, ${ }^{1}$ Rohan Jha ${ }^{2}$ \\ ${ }^{1}$ Department of Community Medicine, ${ }^{2}$ Department of Emergency and General Practice, College of Medical Sciences- \\ Teaching Hospital, Bharatpur, Chitwan, Nepal.
}

\begin{abstract}
Background: Diabetes is an important public health problem as global prevalence of diabetes has nearly doubled reflecting an increase in risk factors like overweight or obesity and dyslipidemia. Both obesity and dyslipidemia share a common pathogenesis associated with "insulin resistance". Thus the aim of this study is to find out correlation between BMI and lipid profile in type 2 diabetics. Materials and Methods: A cross-sectional study was conducted among 136 type 2 diabetes patients visiting the Diabetes Clinic of College of Medical Sciences, Bharatpur, Nepal during Jan-Dec 2017 and who went through lipid profile testing. The information were taken from hospital records. To find the significant association between categorical variables chi-square test was used. $\mathrm{P}$ -value less than 0.05 were considered as statistically significant. To find the association between continuous variables correlation was used. Results: Out of 136 diabetic patients $77.2 \%$ of patients were either overweight or obese.92.6\% of patients had dyslipidemia. Among which 58.1\% had high TG levels, 56.6\% had high LDL levels, $34.6 \%$ had high TC levels and 44.9\% had low HDL levels. The overall mean \pm SD of age was 54.54 \pm 12.03 years and of BMI was $28.54 \pm 4.57$. Positive correlation was seen between BMI with LDL levels and negative correlation with HDL levels. The correlation with other lipid profile parameters were negative. These correlations were found to be statistically not significant. But statistically significant association was seen between gender with weight, total cholesterol and HDL levels. Conclusions: Obesity and dyslipidemia were highly prevalent. As BMI increases LDL levels increases and HDL levels decreases. Also increased weight and abnormal lipid levels of total cholesterol and HDL were found significantly higher among females than males.
\end{abstract}

Keywords: body mass index; lipid profile; type 2 diabetes; HDL; LDL.

\section{INTRODUCTION}

Diabetes is a serious, chronic disease that occurs either when the pancreas does not produce enough insulin or when the body cannot effectively use the insulin it produces. Diabetes is an important public health problem as global prevalence of diabetes has nearly doubled since 1980 , rising from $4.7 \%$ to $8.5 \%$ in the adult population especially in low and middle-income countries. This reflects an increase in associated risk factors such as being overweight or obese which is strongly linked to diabetes. Populations in South-East Asia, develop diabetes at a lower level of body mass index (BMI) than populations of European origin. ${ }^{1}$

Dyslipidemia is also common in Diabetes Mellitus (DM), as both insulin deficiency and resistance affects enzymes and pathways of lipid metabolism. Diabetic dyslipidemia is characterized by raised triglycerides, low highdensity lipoprotein and raised low density lipoprotein particles. It may be present at the diagnosis of T2DM and it is a component of the metabolic syndrome. ${ }^{2}$ It has been established that BMI is a significant predictor of cardiovascular disease and type 2 diabetes mellitus. Association of lipid profiles is reported with lifestyle, age, intraabdominal adiposity, obesity and BMI. ${ }^{3}$ Numerous epidemiological studies have demonstrated a direct correlation between increasing BMI and elevated total cholesterol (TC), low-density lipoprotein cholesterol (LDL), and triglycerides (TG) and an inverse relationship with high density lipoprotein cholesterol (HDL). Recently, observational studies of obese patients have confirmed a correlation between BMI and TG or HDL, but not with LDL levels. These findings have raised the question of a possible "obesity paradox" where LDL levels may plateau or even fall with extreme levels of BMI. ${ }^{4}$ To account for the correlation between obesity and T2DM, BMI has been introduced as a composite covariate for adjustment in T2DM studies. In developed countries, subjects with a BMI of $25 \mathrm{~kg} /$

Correspondence: Dr. Prerna Bansal, Department of Community Medicine, College of Medical Sciences, Bharatpur, Chitwan, Nepal. Email: drprernabg@gmail.com. Phone: +977-9841529167. ORCID: https://orcid.org/0000-00017876-6637 DOI: 10.3126/jcmsn.v14i4.21997. Article received: 2018-11-11. Article accepted: 2018-12-10. 
Bansal et al. Correlation Between Body Mass Index and Lipid Profile in a Diabetic Population..

$\mathrm{m}^{2}$ are defined as overweight and those with a BMI $30 \mathrm{~kg} / \mathrm{m}^{2}$ are defined as obese, and there are good associations and positive predictive effects between BMI and obesity-related chronic diseases. However, it is also reported that most patients with type 2 diabetes could have dyslipidemia at varying degrees, characterized by increased levels of TG and decreased serum HDL. When this characteristic lipid profile is seen in T2DM, it is referred to as diabetic dyslipidemia and confers a risk of CVD. Insulin resistance and T2DM are generally accompanied by low levels of HDL and high TG. Both obesity and dyslipidemia are closely related to T2DM and share a common pathogenesis associated with "insulin resistance". 5 Thus the aim of this study is to find out correlation between BMI and lipid profile in a diabetic population of this region.

\section{MATERIALS AND METHODS}

A cross-sectional study was conducted on patients visiting the Diabetes Clinic of College of Medical Sciences, Bharatpur, Nepal during January 2017 to December 2017. Sample size was determined by using the formula $\mathrm{n}=\left(\mathrm{z}^{2} \times \mathrm{pq}\right) / \mathrm{e}^{2}$. The prevalence of type 2 Diabetes cases in Nepal is $8.4 \%{ }^{6}$ So, considering $\mathrm{p}=0.084$ and $\mathrm{q}=0.916$. The $\mathrm{z}$-score value at $95 \%$ Confidence interval is 1.96 . The desirable error was $5 \%$, the required minimum sample size of this study was 118 , and including $10 \%$ non response error the sample size was 136 . The total of 136 type 2 diabetes patients visited the Diabetes clinic during the study duration and went through lipid profile testing. Their information were collected from hospital records for the study. Ethical approval was taken from Institutional Review Committee of College of Medical Sciences.

BMI was obtained by dividing weight (in kilograms) by the square of height (in metres) i.e. $\mathrm{kg} / \mathrm{m}^{2}$. Lipid Profile normal reference values were taken as total cholesterol $(<200 \mathrm{mg} / \mathrm{dl})$, triglycerides $(<150 \mathrm{mg} / \mathrm{l})$, HDL ( $>40 \mathrm{mg} / \mathrm{dl})$, LDL $(<100 \mathrm{mg} / \mathrm{dl})$ and VLDL $(10$ $-50 \mathrm{mg} / \mathrm{dl}$ ) respectively. ${ }^{7}$ The collected data was first checked for completeness and consistency. Different variables were coded, entered and analysed by using SPSS version 16 software. The entered data were cleaned and edited before subsequent analysis. To find the significant association between categorical variables chi-square test was used. P-value less than 0.05 were considered as statistically significant. To find the association between continuous variables correlation was used.

\section{RESULTS}

Majority (61\%) of the patients belonged to 41 to 60 years age group. Gender wise there were more males
$(59.6 \%)$ than females $(40.4 \%)$. Body mass index (BMI) distribution found majority (39.7\%) of patients to be overweight and $37.5 \%$ of patients to be obese. Among obese $78.4 \%$ of patients had class 1 obesity (Table 1 ).

\begin{tabular}{|c|c|c|}
\hline & Frequency & Percent \\
\hline \multicolumn{3}{|l|}{ Age (years) } \\
\hline$<20$ & 1 & 0.7 \\
\hline $20-40$ & 13 & 9.6 \\
\hline $41-60$ & 83 & 61.0 \\
\hline$>60$ & 39 & 28.7 \\
\hline \multicolumn{3}{|l|}{ Gender } \\
\hline Female & 55 & 40.4 \\
\hline Male & 81 & 59.6 \\
\hline \multicolumn{3}{|l|}{ BMI $\left(\mathrm{kg} / \mathrm{m}^{2}\right)$} \\
\hline Normal weight (18.5-24.9) & 31 & 22.8 \\
\hline Overweight (25-29.9) & 54 & 39.7 \\
\hline Obesity $(\geq 30)$ & 51 & 37.5 \\
\hline -Class 1 Obesity $(\geq 30-34.9)$ & 40 & 78.4 \\
\hline -Class 2 Obesity (35-39.9) & 9 & 17.6 \\
\hline -Class 3 Obesity $(\geq 40)$ & 2 & 3.9 \\
\hline
\end{tabular}

Lipid profile of the patients shows that majority $(58.1 \%)$ of the patients had high TG levels. Similarly, $56.6 \%$ of patients had high LDL levels, $34.6 \%$ had high total cholesterol levels. Whereas, $44.9 \%$ of patients had low HDL levels (Table 2).

\begin{tabular}{|lcc|}
\hline \multicolumn{3}{c|}{ Table 2. Lipid Profile of the patients (n=136). } \\
\hline Total cholesterol (TC) & Frequency & Percent \\
Normal & 89 & 65.4 \\
High & 47 & 34.6 \\
Triglycerides (TG) & & \\
Normal & 57 & 41.9 \\
High & 79 & 58.1 \\
HDL & & \\
Normal & 75 & 55.1 \\
Low & 61 & 44.9 \\
LDL & & \\
Normal & 59 & 43.4 \\
High & 77 & 56.6 \\
VLDL & & \\
Normal & 114 & 83.8 \\
High & 22 & 16.2 \\
\hline
\end{tabular}


Bansal et al. Correlation Between Body Mass Index and Lipid Profile in a Diabetic Population..

The overall mean \pm SD of age was $54.54 \pm 12.03$ years. The mean \pm SD age of females was $52.31 \pm 12.40$ years and mean age of males was $56.06 \pm 11.61$ years. The overall mean \pm SD of BMI was $28.54 \pm 4.57$. The overall mean \pm SD of TG levels was $182.56 \pm 91.14$, whereas the mean \pm SD TG levels of females was $195.65 \pm 107.31$ and of males was $173.68 \pm 77.76$. The overall mean \pm SD of LDL levels was $105.76 \pm 37.69$, whereas the mean \pm SD LDL levels of females was $109.03 \pm 38.45$ and of males was $103.54 \pm 37.24$ (Table 3). between age with all parameters. These correlations were found to be statistically not significant (Table 6).

\begin{tabular}{|c|c|c|c|c|c|c|c|}
\hline \multicolumn{8}{|c|}{$\begin{array}{l}\text { Table 6. Correlation between age with lipid profile and } \\
\text { BMI. }\end{array}$} \\
\hline \multirow{3}{*}{ 察 } & & BMI & $\mathrm{TC}$ & TG & HDL & LDL & $\begin{array}{l}\text { VL } \\
\text { DL }\end{array}$ \\
\hline & $\begin{array}{l}\text { Pearson } \\
\text { Correla- } \\
\text { tion }\end{array}$ & -.02 & -.07 & -.12 & -.04 & -.01 & -.13 \\
\hline & p-value & .77 & .36 & .15 & .64 & .86 & .11 \\
\hline
\end{tabular}

Table 3. Gender wise mean and standard deviation of continuous variables.

\begin{tabular}{|lllllll|}
\hline \multicolumn{2}{l}{ Table 3. Gender wise mean and standard deviation of continuous variables. } \\
\hline Variable & Over All & \multicolumn{3}{c}{ Female } & Male & \\
& Mean & Std. Deviation & Mean & Std. Deviation & Mean & Std. Deviation \\
Age & 54.54 & 12.03 & 52.31 & 12.40 & 56.06 & 11.61 \\
BMI & 28.54 & 4.57 & 28.60 & 5.24 & 27.59 & 4.08 \\
Total cholesterol (TC) & 185.77 & 41.34 & 195.17 & 39.88 & 179.38 & 41.33 \\
TG & 182.56 & 91.14 & 195.65 & 107.31 & 173.68 & 77.76 \\
HDL & 43.73 & 10.20 & 46.44 & 10.86 & 41.89 & 9.36 \\
LDL & 105.76 & 37.69 & 109.03 & 38.45 & 103.54 & 37.24 \\
VLDL & 36.76 & 18.38 & 39.06 & 21.39 & 35.20 & 15.97 \\
\hline
\end{tabular}

The correlation between BMI with lipid profile shows that there is positive correlation between BMI with LDL levels and negative correlation with HDL levels. The correlation with other lipid profile parameters were negative. These correlations were found to be statistically not significant (Table 4).

\begin{tabular}{|ccccccc|}
\hline \multicolumn{6}{|c|}{ Table 4. Correlation between BMI and lipid profile. } \\
\hline BMI & $\begin{array}{l}\text { Pearson } \\
\text { Correla- } \\
\text { tion }\end{array}$ & -.010 & -.085 & -.050 & .069 & -.098 \\
& P-value & .905 & .326 & .562 & .426 & .256 \\
\hline
\end{tabular}

The comparison between continuous variables (Weight, BMI, Total Cholesterol, TG, HDL, LDL and VLDL) with gender shows that there is statistically significant association between weight, total cholesterol and HDL levels with gender (Table 5).

\begin{tabular}{|llll|}
\hline \multicolumn{4}{|l|}{ Table 5. Comparison of variables according to gender. } \\
\hline Variable & t-value & df & p-value \\
Weight & 3.984 & 130 & $<0.001^{*}$ \\
BMI & -.119 & 97 & .905 \\
Total Cholesterol (TC) & -2.232 & 119 & $.027^{*}$ \\
TG & -1.304 & 92 & .196 \\
HDL & -2.607 & 134 & $.010^{*}$ \\
LDL & -.832 & 134 & .407 \\
VLDL & -1.205 & 134 & .230 \\
\hline
\end{tabular}

*statistically significant at $5 \%$ level of significance.

The correlation between age with lipid profile and BMI shows that there is negative correlation

\section{DISCUSSION}

In our study, the majority $(61 \%)$ of the patients belonged to 41 to 60 years age group. Gender wise there were more males (59.6\%) than females (40.4\%). Chamba et al., also found $50.42 \%$ patients were males. ${ }^{8}$ Whereas Zeqollari et al., found more females $(56 \%)$ than males $(44 \%) .{ }^{9}$ The overall mean \pm SD of age in present study was $54.54 \pm 12.03$ years, that of females was $52.31 \pm 12.40$ years and of males was $56.06 \pm 11.61$ years. Likewise, some other studies also found similar values of mean \pm SD of age overall, in males and in females. ${ }^{2,8,9}$

None of the patients were underweight in this study. Whereas, $22.8 \%$ were normal weight, $39.7 \%$ were overweight and $37.5 \%$ of patients were obese. So, about $77.2 \%$ of patients were either overweight or obese. Among which $78.4 \%$ of patients had class 1 obesity. Omotoye et al., also found none of the participant to be underweight, $36.0 \%$ were normal weight and $64 \%$ either overweight or obese. ${ }^{2}$ In our study the overall mean $\pm \mathrm{SD}$ of BMI as well as in females and males were $28.54 \pm 4.57,28.60 \pm 5.24$, $27.59 \pm 4.08$ respectively. Thus, all mean values were observed to be overweight. Chamba et al., also found similar findings of mean $\pm \mathrm{SD}$ of BMI, overall was $27.9 \pm 5.0$, in females was $29.4 \pm 5.5$ and in males was $26 \pm 3.8 .^{8}$

In the present study, $92.6 \%$ of patients had dyslipidemia. Similarly, Chamba et al., also found diabetic dyslipidemia in $94.1 \%$ of patients. ${ }^{8} 58.1 \%$ 
of the patients had high TG levels, $56.6 \%$ of patients had high LDL levels, $34.6 \%$ had high TC levels and $44.9 \%$ of patients had low HDL levels. Similarly, in study by Omotoye et al., $34 \%$ had high TC levels, $12 \%$ had high TG levels and $66.0 \%$ had low HDL levels. ${ }^{2}$ In present study the overall mean \pm SD of TG levels was 182.56 \pm 91.14 , whereas the mean TG levels of females was $195.65 \pm 107.31$ and of males was 173.68 \pm 77.76 . The overall mean \pm SD of LDL levels was $105.76 \pm 37.69$, whereas the mean LDL levels of females was $109.03 \pm 38.45$ and of males was $103.54 \pm 37.24$. Similar findings of means values of different lipids were seen in one another study by Rajput et al. ${ }^{10}$

The present study found correlation between BMI with LDL levels (Pearson correlation coefficient $=0.069, \mathrm{p}=0.426$ ) and HDL levels ( $\mathrm{r}=-$ $0.050, p=0.562$ ). There was no correlation found of BMI with TC $(\mathrm{r}=-0.010, \mathrm{p}=0.905), \mathrm{TG}(\mathrm{r}=-0.085$, $\mathrm{p}=0.326)$ and VLDL $(\mathrm{r}=-0.098, \mathrm{p}=0.256)$ levels. However, all these correlations were not statistically significant. Likewise in a study by Shamai et al., there was an association between BMI and HDL (Pearson correlation coefficient=$0.267, \quad \mathrm{p}<0.001)$ and $\mathrm{TG} \quad$ (correlation coefficient $=0.163, \mathrm{p}=0.006$ ). But there was no association between BMI and TC (correlation coefficient $=0.002, \mathrm{p}=0.96$ ) or $\mathrm{LDL}$ (correlation coefficient $=0.078, \mathrm{p}=0.06$ ) levels. ${ }^{4}$ So, further more epidemiological studies are required to find out whether or not BMI is correlated with all lipid parameters in diabetics and also correlation of other factors with dyslipidemia has to be studied.

We found statistically significant association between gender with weight $(\mathrm{p}=<0.001), \mathrm{TC}$ $(p=0.27)$ and HDL $(p=0.010)$ levels. Weight, TC levels and HDL levels all were seen higher in females than in males. Likewise, Omotoye et al., found among the males BMI was positively correlated with HDL, LDL, TC and TG whereas in females BMI positively correlated with HDLand LDL but negatively correlate with $\mathrm{TC}$ and $\mathrm{TG}^{2}{ }^{2} \mathrm{The}$ present study showed that correlation between age with lipid profile parameters and BMI were negative correlation. These correlations were found to be statistically not significant. Whereas, Omotoye et al., had found correlation between age with TC and LDL levels to be positive, and between age with HDL and TG to be negative which is similar finding as our study. ${ }^{2}$

\section{CONCLUSIONS}

Both the risk factors, obesity and dyslipidemia were seen highly prevalent in the type 2 diabetic population. As BMI increases LDL levels also increases and as BMI increases HDL levels decreases. Also increased weight and abnormal lipid levels of total cholesterol and HDL were found significantly higher among type 2 diabetic females than males.

\section{Conflict of Interest: None.}

index,and waistline in Chinese patients with type 2diabetes mellitus. Clinical Interventions in Aging 2016 Apr 18;11:445-452.

6. Gyawali B, Sharma R, Neupane D, Mishra SR, Teijlingen EV, Kallestrup P. Prevalence of type 2 diabetes in Nepal: a systematic review and meta-analysis from 2000 to 2014. Glob Health Action 2015 Nov 26;8:29088.http:// dx.doi.org/10.3402/gha.v8.29088

7. Providence Health and Services Oregon and Southwest Washington. Lipid profile (cholesterol and triglycerides). [Internet]. 2018 [cited 2018Dec11]. Available from: https:// oregon.providence.org/our-services/l/lipidprofile-cholesterol-and-triglycerides/

8. Nyasatu G. Chamba, Elichilia R Shao, Tolbert Sonda,Isaack A. Lyaruu. Lipid Profile of Type 2 Diabetic Patients at a Tertiary Hospital inTanzania: Cross Sectional Study. J Endocrinol Diab. $2017 \quad 4(1): 1-6 . \quad$ http:// dx.doi.org/10.15226/2374-6890/4/1/00170 
Bansal et al. Correlation Between Body Mass Index and Lipid Profile in a Diabetic Population..

9. Zeqollari A, Spahiu K, Vyshka G, Çakërri L. Lipid Profile in Diabetes Mellitus Type 2 Patients in Albania and the Correlation with BMI, Hypertension and Hepatosteatosis. J Family Med Community Health 2014 1(4):1018.
10. Rajput DPR, Shah JY, Singh P, Jain S. Evaluation of dyslipidemia in type 2 diabetes mellitus. Asian Journal Of Medical Sciences. 2015 Nov-Dec;6(6):16-19.

Citation: Bansal P, Upadhyay HP, Jha R. Correlation Between Body Mass Index and Lipid Profile in a Diabetic Population of Central Nepal. JCMS Nepal. 2018;14(4):184-8. 